\title{
Applicability of multi-color image analysis for quantifying the fluorescein concentration profile in low-permeability media
}

\author{
CHANGMIN KIM ${ }^{1}$, MINJUNE YANG ${ }^{2, *}$
}

${ }^{1}$ Division of Earth Environmental System Sciences, Pukyong National University, Busan, Korea

(changmin_kim@pukyong.ac.kr)

${ }^{2}$ Department of Earth and Environmental Sciences, Pukyong National University, Busan 48513, South Korea

(*correspondence: minjune@pknu.ac.kr)

Identifying the contaminant behavior inside the lowpermeability media has been considered as a challenging issue that proceeds for large time series in small spatial variation. In this study, the multi-color image analysis was performed to quantify fluorescein concentration profiles in three types of clay (kaolinite, montmorillonite, bentonite) by measuring the color intensities of the fluorescein solution. Each clay was mixed with fluorescein solutions having 7 different concentrations $(0,1,10,100,500,1000$, and 2000 $\mathrm{mg} / \mathrm{L})$, respectively. The images of the acrylic box $(3 \mathrm{~cm} \times 3$ $\mathrm{cm} \times 1 \mathrm{~cm})$ filled with mixture were taken and split into RGB color channels to measure the color intensities. Simple exponential and polynomial relations were found between green and blue color intensities and fluorescein concentrations. The green color intensities for montmorillonite decreased from 0.836 to 0.310 , and the blue color intensities for kaolinite and bentonite decreased from 0.832 and 0.367 to 0.171 and 0.008 with an increase in fluorescein concentrations from 100 to $2000 \mathrm{mg} / \mathrm{L}$ and 0 to $2000 \mathrm{mg} / \mathrm{L}$ respectively. The application of the multi-color image analysis method for kaolinite and montmorillonite can be possible at a fluorescein concentration range from 0 to $2000 \mathrm{mg} / \mathrm{L}$. However, fluorescein concentrations for bentonite can only be estimated range from 0 to $500 \mathrm{mg} / \mathrm{L}$ using the image analysis. 